\title{
Q\&A: Hervé This on flavour and perception
}

French chemist Hervé This is a pioneer of the field of molecular gastronomy, the science of cooking. From perfecting the boiled egg to making custards with meat proteins, he has advised top chefs worldwide. He tells Nature why he is moving on to 'note-by-note' cuisine using compounds to build taste and smells, and why turkey is best cooked in the dishwasher.

\begin{abstract}
Why do some meals taste better than others?

The principles of cuisine are love, art and technique: perfect technique without love and companionship is lost. A poor sandwich shared with good friends will taste better than dinner in a three-star Michelin restaurant shared by an arguing couple. Primates generally avoid bitter tastes such as beer. But the sensory punishment of drinking bitter beer is more than offset by the social reward of being in a group.
\end{abstract}

Does every ingredient have a unique taste? There is no such thing as unique taste. It is a phantasm. The taste of chicken, for example, does not exist as a pure concept. Chicken has many different tastes, depending on the type of chicken and on the way you cook it.

\section{Should dishes be put together from scratch, molecule by molecule? \\ Meat, fish, fruits and vegetables are} organized mixtures of compounds. Cooking traditionally means mixing mixtures, and is not precise. This is why I proposed the concept of note-by-note cooking - using specific compounds to build consistency, taste and odour. It is difficult, but a huge unexplored continent is ahead of us.

\section{Are foods from different regions the same chemically? \\ Geography can alter the flavour of a food produced with exactly the same methods. My friend and colleague Jean-Baptiste Coulon, at the French National Institute for Agricultural Research in Clermont-Ferrand, has shown that the flavour of reblochon cheese differs depending on the cow's grazing location, and that molecular differences are responsible. Here in France, the Appellation d'Origine Contrôlée (AOC) system [which certifies a food's geographical origin] is right and there is a measurable difference between locations - a real terroir.}

\section{How would local food producers} contribute to note-by-note cooking? Take, for example, this bottle of powder made from the phenolic acids from syrah grapes. A farmer growing grapes for wine production alone will probably lose money. But if you make these phenolics and sell

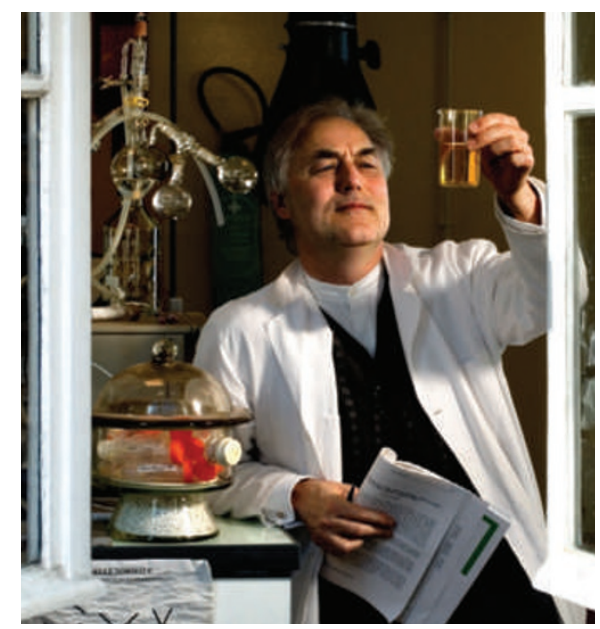

them to chefs doing note-by-note cooking, the farmer could make a profit while supporting sustainable agriculture and working within the traditional AOC system.

\section{The taste of your famous Chantilly chocolate mousse is more intense than the ingredients alone. Why is this?}

The importance of microstructure on flavour is an area of active and exciting research. In an emulsion of oil in water, such as a dressing, large oil droplets enhance the perception of oil and small droplets enhance the perception of odorant molecules that dissolve in the water phase. The molecular mechanism is still unclear, but the effect is well established. Also, the more surface area you have, the more odorant molecules are released. The same holds for foams. So, if your preparation contains many small air bubbles, this increases the flavour of the chocolate.

\section{How might chefs retain the odorant molecules that are released in cooking vapours?}

The food industry already recaptures and reincorporates 'essential oils' that are lost during cooking processes. As a result, jams and orange juice, for example, are now much better. After decades of my promoting it, chefs have recently taken up using rotary evaporators - a device available in chemistry-supply stores and usually used for distillation - to extract these oftenlost essences. Using a technology that was never designed for cooking, chefs can create intense sensations such as strawberry or coffee water. The home cook could in principle do the same.

\section{Another professional technique is to cook food for long periods at low temperatures} in a vacuum-sealed bag. How might a home chef emulate this 'sous-vide' method?

Use the dishwasher! For the next holiday meal, I recommend that you prepare two turkeys. Cook one in the dishwasher, in a plastic bag, for several cycles of your machine. In this way, you can get low temperatures. Butterfly the other turkey and cook it on the grill, creating the maximum expanse of delicious crispy skin. Then serve the moist, flavourful meat from the dishwasher turkey with the grilled skin. A good accompaniment would be foie gras, also cooked in the dishwasher at low temperature.

\section{What have you found by studying the cooking process of meat?}

Our experiments have clearly shown that most meat cannot absorb liquids, be they acidic or basic, hot or cold. This finding has shocked many. But we have recently discovered that certain kinds of meat - those with low amounts of collagenic tissue, such as beef fillet - can absorb liquids through capillary action. This reconciles the results of various past scientific studies.

\section{Are any foods poor candidates for molecular-gastronomy research?} I try not to work on cheese, wine, bread or sausages - the microbiology is too complicated. Onions and carrots are better subjects, but progress is slow. After two $\mathrm{PhD}$ projects studying the creation of carrot stock, we are only beginning to understand the molecular diffusion processes involved. Interview by Michael White, associate editor at Nature.

Hervé This's latest book is The Science of the Oven (Columbia University Press, 2009). For Q\&As with molecular chefs Harold McGee and Ferran Adrià, see go.nature.com/3cs5Yg and go.nature.com/FzrNmn.

Correction
The brief review of William Langewiesche's book
Fly By Wire (Nature 463, 882; 2010) incorrectly
spelled the first name of Captain Sullenberger as
"Chelsey". It should have read "Chesley".

